\title{
ANÁLISIS Y EVOLUCIÓN DE LOS DELITOS DE ODIO EN ESPAÑA (2011-2015)
}

\author{
Anna I. LÓPEZ ORTEGA \\ Universitat de València \\ alor5@uv.es
}

\section{ANALYSIS AND EVOLUTION OF HATE CRIMES IN SPAIN (2011-2015)}

Resumen: El artículo realiza por primera vez una radiografía de los delitos de odio en España a partir de un análisis exhaustivo de la evolución de las cifras en los últimos cinco años. En 2015 se han contabilizado 1.285 delitos de odio y 1.273 víctimas. Los agresores son mayoritariamente varones, entre 18 y 35 años y ocho de cada diez son nacionales. El 52\% de las víctimas son mujeres y han nacido en España, aunque cada vez más el origen de la víctima es más diverso tanto en su país de origen como en su religión. Para su análisis, se ha utilizado metodología cuantitativa y se han seleccionado variables relevantes como la edad, el sexo, la nacionalidad y la distribución de los delitos por comunidades autónomas. El estudio aporta nuevas cifras de esta tipología de delitos en el caso español y apunta las posibles causas de su crecimiento.

Abstract: The first article provides a snapshot of hate crimes in Spain from a comprehensive analysis of the evolution of the figures in the last five years. In 2015 they have been counted 1.285 hate crimes and 1.273 victims. The attackers are mostly men between 18 and 35 years and eight out of ten are national. 52\% of victims are women and were born in Spain, but increasingly the origin of the victim is more diverse both in their country of origin and religion. For analysis it has been used quantitative methodology and have been selected relevant variables such as age, sex, nationality and distribution of crimes by autonomous communities. The study provides new figures of this type of crime in the Spanish case and points out the possible causes of its growth.

Palabras clave: Delitos De Odio, Discurso Del Odio, Extrema Derecha, Xenofobia, Islamofobia, Radicalismos, Racismo Hate Crimes, Hate Speech, Extreme Right, Xenophobia, Islamophobia Racism, Radicalism 


\section{Introducción}

El concepto de delito de odio era desconocido hace una década. Precisamente este desconocimiento ha provocado un debate en torno a su propia existencia, justificación y regulación por dos motivos: la determinación sobre qué grupos o personas deberían estar consideradas como víctimas del odio y la dificultad de su consenso internacional, ya que en muchas ocasiones en una cuestión de la problemática interna de los estados.

La definición de delito de odio aprobada desde el Consejo Ministerial de la Organización para la Seguridad y la Cooperación en Europea ${ }^{1}$ (OSCE) celebrado en Maastricht en 2003 define los delitos de odio como:

"toda infracción penal, incluidas las cometidas contra las personas o la propiedad, donde el bien jurídico protegido, se elige por su, real o percibida, conexión, simpatía, filiación, apoyo o pertenencia a un grupo. Este grupo se basa en una característica común de sus miembros, como su "raza", real o percibida, el origen nacional o étnico, el lenguaje, el color, la religión, la edad, la discapacidad, la orientación sexual, u otro factor similar". (Decisión $n^{\circ} 4 / 03$ de la OSCE).

Además se recomendaba a todos los estados "recopilar y mantener registros sobre información relevante y datos estadísticos sobre delitos de odio, incluyendo manifestaciones violentas de racismo, xenofobia, discriminación, y antisemitismo" y encomendaba a la Oficina Internacional de Derechos Humanos (OIDDH) que fuera el punto de recopilación de las estadísticas de los estados miembros y que informara regularmente. Sin embargo, en este primer intento de reconocimiento sólo participan cuatro países: Alemania, Dinamarca, Austria y Finlandia.

Este consenso logrado en Maastrich por parte de todos los países y organismos de la Unión Europea permite las primeras investigaciones en la identificación de este tipo de delito en el ámbito europeo. Por este motivo, este artículo también adoptará esta definición de la OSCE para analizar el caso español.

Una de las características que amplifica la peligrosidad de este discurso es su propagación a través de las nuevas tecnologías, el denominado "ciber odio". El Comité Europeo de Ministros del Consejo de Europa considera que el término "discurso de odio" abarca todas las formas de expresión que propaguen, inciten, promuevan o justifiquen el odio racial, la xenofobia, el antisemitismo u otras las formas de odio, incluida la expresada a través del nacionalismo y el etnocentrismo y la hostilidad contra las minorías y los inmigrantes (Rec. de la Comisión, de 20 de septiembre de 2012).

Además añade que este contenido se difunde también en páginas webs (blogs, juegos on line, música y vídeo principalmente), redes sociales y mensajes de texto que permiten la difusión masiva de sus ideas y se amparan en las dificultades que ofrecen su investigación y persecución cuando sus autores se encuentran en países en los que este tipo de comportamientos no son delictivos.

Algunos ejemplos de este tipo de delito en España se denuncian en el Informe Raxen elaborado por Movimiento contra la Intolerancia (2014: 80) donde recogen páginas de facebook como "Mata a los negros", con la imagen de un negro colgando de una soga, "Odio a las gitanos", "Contra la invasión inmigrante", "Rudolf Hess vive", "Mata gays", "Hay que

\footnotetext{
1 La OSCE ha tomado una enfoque integral de la seguridad desde su creación en 1975, según la Conferencia sobre la Seguridad y la Cooperación en Europa. Sus funciones incluyen no sólo a los aspectos político-militares y económicos de la seguridad, sino también la dimensión humana. La dimensión humana incluye la protección de los recursos humanos los derechos y las libertades fundamentales, la promoción del estado de derecho y democrático instituciones y la tolerancia y la no discriminación. Esta dimensión se desarrolla fundamentalmente a través de la Oficina para la Instituciones Democráticas y Derechos Humanos con sede en Varsovia.
} 
legalizar la violación”, "Odio a los maricones, las putas y los policías” y centenares de páginas donde se incita al odio, la discriminación o la violencia hacia colectivos vulnerables.

Otro de los factores que contribuye a la propagación del discurso del odio es el éxito electoral de partidos políticos y movimientos de extrema derecha en toda Europa. Destaca el discurso del Front National, el partido más votado en las elecciones europeas celebradas en 2015. Su líder Marine Le Pen fue juzgada el 20 de noviembre de 2015 por incitar al odio racial contra los musulmanes a raíz de las declaraciones públicas realizadas en diciembre de 2010 cuando afirmó "lo siento, pero para todos esos a los que tanto les gusta recordar la II Guerra Mundial, si se trata de hablar de la Ocupación, se podría comparar. Porque esto es una ocupación del territorio. Cierto, no hay blindados, tampoco soldados, pero es igualmente una ocupación" (Canas, 2015: 1).

Desde el año 2014, según estadísticas difundidas por el gobierno galo, se han duplicado los actos racistas y xenófobos en Francia en comparación con 2013, incluida la profanación de cementerios. El Observatorio contra la Islamofobia del Consejo de Francés de Culto Musulmán (CFCM) ha publicado la comisión de 222 actos racistas e islamófobos en los primeros tres meses de 2015, incluidos balazos o lanzamientos de granadas a centros de culto, frente a los 37 que registró en el mismo periodo en 2014 (Vicente, 2015: 2).

Para luchar contra estos delitos, el gobierno francés aprobó en enero de 2015 un plan jurídico, policial y educativo para luchar contra la islamofobia y la intolerancia, convertida en "una causa nacional" según el primer ministro francés, Manuel Valls. Entre las 40 medidas del proyecto, destaca la creación de una unidad policial específica para perseguir esos delitos, sobre todo en la Red y la consideración del componente racista o antisemita en cualquier delito como una circunstancia agravante. (Yárnoz, 2015:1).

La argumentación radical de estos partidos ha contagiado a otras formaciones españolas que han comenzado a imitar alguna de sus prácticas y programas electorales, caracterizados por su odio hacia la población inmigrante: España 2000, Palataforma per Cataluña o Democracia Nacional. En 2014 la Plataforma Contra la Islamofobía denunció ante la Fiscalía de delitos de odio de la Comunidad Valenciana el reparto de alimentos "sólo para nacionales" en el barrio de Orriols de Valencia por la ONG María Dolores Navarro, relacionada con el partido España 2000. También denunció el reparto de un panfleto xenófobo en farmacias valencianas que vinculaba la inmigración con la falta de recursos en sanidad, tambiém se handetectado pintadas con símbolos nazis en la Pobla de Farnals, Torrent o Silla, entre otras localidades valencianas (Informe Raxen, 2014: 56).

Junto a los partidos políticos extremistas que propagan el odio, han aparecido movimientos con el objetivo de frenar la supuesta islamización europea. Es el caso de Pegida en Alemania, autobautizados como patriotas y que han convocado sucesivas manifestaciones en las ciudades de Leipzig, Munich y Hannover durante 2015 con el apoyo de 100.000 alemanes. Un movimiento que se ha extendido rápidamente a otros países como Suiza y España, concretamente en Valencia ${ }^{2}$.

En el caso español, el delito de odio no está incluido la normativa penal. Sin embargo, desde la Fiscalía de Delitos de Odio de Barcelona se establecen diversos preceptos del código penal que se enmarcarían dentro de la categoría de los delitos de odio, según la definción aprobada por la OSCE en diciembre de 2003 (Decisión 4/03 del Consejo Ministerial de la OSCE) y aceptada por el Ministerio de Interior español en los informes específicos sobre los delitos de odio 2013 y 2014.

Se trata del artículo 22.4, que es aplicable a todo aquel que delinque por motivos racistas, antisemitas o en base a otra clase de discriminación referente a la ideología, religión o

2El 16 de enero de 2015 un autodenominado "patriota europeo" vinculado al partido España 2000 convocó la manifestación en Valencia "Valentía contra el Islam", con el objetivo de "manifestar el rechazo al terrorismo islamista derivado de la aplicación violenta de la doctrina de Mahoma" (Parrilla, J, 2015:1) 
creencias de la víctima, su etnia, raza o nación a la que pertenezca, sexo, orientación sexual, enfermedad o minusvalía que padezca.

El precepto 170.1 castiga las amenazas dirigidas a atemorizar a poblaciones, grupos étnicos, culturales o religiosos o colectivos sociales. El 314 pena a los que produzcan una grave discriminación en el empleo, público o privado, contra alguna persona, entre otras causas, por razón de su ideología, religión, creencias, etnia, raza o nación.

El 510 castiga con penas de hasta tres años de prisión los denominados delitos de incitación al odio o a la violencia, contra grupos o asociaciones, por motivos racistas, antisemitas, ideológicos, religiosos, de raza, etnia o nacionalidad, aplicable también a los que con conocimiento de su falsedad o temerario desprecio hacia la verdad, difundieran informaciones injuriosas sobre estos grupos o asociaciones. Los artículos 511 y 512 regulan la denegación de prestaciones a personas o asociaciones, siempre y cuando éstas tengan derecho a ellas, por razón de su ideología, religión, nacionalidad, etnia o raza.

Finalmente, el artículo 607 que regula con la pena de hasta dos años de prisión, a aquellos que difundieran por cualquier medio de ideas o doctrinas que nieguen o justifiquen los delitos de genocidio o pretendan la rehabilitación de regímenes o instituciones que amparen prácticas generadoras de los mismos.

A pesar de esta lista de preceptos que contempla los supuestos de delitos de odio, desde la Fiscalía de Delitos de Odio se critica que se encuentren dispersos por el Código Penal, que su redacción sea deficiente y que estén faltos de coherencia sistémica. (Memoria del Servicio de Delitos de Odio y Discriminación de la Fiscalía de Barcelona, 2010: 5:), (Memoria del Servicio de Delitos de Odio y Discriminación de la Fiscalía de Barcelona, 2011: 11), (Memoria del Servicio de Delitos de Odio y Discriminación de la Fiscalía de Barcelona, 2012: 90).

\section{Primeros intentos de lucha contra los delitos de odio en España}

Desde diversos organismos internacionales manifestaban (hasta 2014) que España era uno de los pocos países de Europa que no registraba este tipo de datos de manera sistemática (ECRI, 2011: 22), (FRA, 2011: 32) y (OIDDH, 2011: 64). También el primer informe de delitos de odio en España publicado en diciembre de 2013 reconoce que "la lucha contra los delitos de odio experimentada en nuestro país desde 2010 es evidente. Este desarrollo ha comportado que España, en el año 2010 pasase a ser uno de los pocos países de la UE que no registraba este tipo de datos de manera sistemática, a estar, entre los cinco primeros países que mejor recogen los datos de este fenómeno según el FRA" (Informe sobre la evolución 2013 de los delitos de odio en España, 2013: 7). No obstante, como se examinará en el siguiente punto, en 2010 se crea la primera oficina Fiscalía de Delitos de Odio de Barcelona y junto el trabajo de organizaciones no gubernamentales inician el proceso de reconocimiento y denuncia.

En 2013 el Ministerio del Interior elabora el primer documento específico sobre los delitos de odio (Informe sobre la evolución 2013 de los delitos de odio en España) y con su publicación manifiesta la preocupación ante este problema. Sin embargo, como se ha señalado anteriormente, en 2010 se crea la primera Fiscalía de Delitos de Odio de Barcelona. Los representantes de la ECRI destacaron el trabajo de esta Fiscalía en el "Cuarto Informe sobre España sobre la situación del racismo y la xenofobia" de 2011 y recomendaron a las autoridades españolas que "evaluaran su eficacia, estudiaran la posibilidad de nombrar más fiscales especiales para combatir la discriminación y los actos de violencia inspirados en el odio y la discriminación en otras partes de España." (ECRI, 2011: 12)

El Servicio catalán ha sido considerado ejemplo de buenas prácticas en el marco del proyecto "Stop Hate Crimes in Europe" financiado por la Unión Europea en el año 2012 y la FRA manifestó en 2013 que es una "práctica prometedora por su proximidad a las víctimas 
a través de las ONGs y destacó "su estrategia de respuesta ante eventos públicos en los que se difunda el discurso del odio" (FRA, 2013: 15)

A partir de 2010, se crearon servicios similares en Madrid y Málaga y el Fiscal General del Estado nombró un Fiscal Delegado para la Tutela Penal de la Igualdad y contra la Discriminación con el objetivo de que éste designara, a su vez, Fiscales Delegados en cada capital de provincia para impulsar y coordinar la actuación del Ministerio Fiscal ante los crímenes de odio y discriminación. Actualmente España cuenta con 50 fiscales especializados en delitos de odio y discriminación.

Además en 2010 el cuerpo de Mossos d'Esquadra en Cataluña implantó el "Procedimiento de hechos delictivos motivados por el odio o la discriminación”. Este protocolo ha consolidado a este cuerpo policial como el primero en España que ha desarrollado una herramienta que permite ofrecer datos estadísticos oficiales sobre delitos y faltas denunciadas en Cataluña con una motivación discriminatoria (Memoria de los Delitos de Odio de Barcelona, 2010: 15).

Por otro lado, la identificación y la lucha de los delitos de odio presenta diversas dificultades derivadas de la falta de reconocimiento de este tipo de delitos a través de estadísticas públicas y oficiales, fundamentales para conocer el volumen aproximado de criminalidad.

Aunque es cierto que en 2011 el Ministerio del Interior realiza modificaciones en el Sistema Estadístico de Criminalidad (SEC) para registrar adecuadamente cualquier acto susceptible de ser calificado como racista o xenófobo, estos datos tienen muchas limitaciones. Entre otras razones, por la ausencia de formación específica de las fuerzas y cuerpos de seguridad del estado, ya que al desconocer este tipo de delitos y sus características, el registro no es fiable ni eficaz. En este sentido, tanto el "Cuarto Informe sobre España sobre la situación del racismo y la xenofobia" como las Memorias de la Fiscalía de odio, reiteran que la formación de los cuerpos policiales, miembros del sistema de justicia e incluso médicos forenses, abogados y personal de seguridad privada es una necesidad en la lucha contra los delitos de odio y la discriminación.

Por otro lado, la Estrategia de Seguridad y Defensa Española incluye desde 2011 y por primera vez a grupos a los extremistas, uno de los principales factores de incitación a este tipo de delito a través de "discurso del odio". En concreto, la estrategia española señala que son "una amenaza para la seguridad del estado" (Ministerio del Interior, 2011: 36).

Una referencia que contrasta con las cifras recogidas en el Informe Raxen elaborado por la organización no gubernamental Movimiento contra la Intolerancia. El documento denuncia la existencia de militantes y simpatizantes en organizaciones de extrema derecha "alegales" y el crecimiento en los últimos cuatro años (de 3.000 a 10.000 militantes y simpatizantes), por encima de los 10.450 que tienen censados en Alemania. Además la Policía y la Guardia Civil han detectado más de 200 grupos de ultraderecha, frente a los apenas 70 reconocidos en los años noventa (Raxen, 2012: 36).

\subsection{Metodología y estructura}

El objetivo principal del estudio es analizar -por primera vez- la evolución de la cifras de los delitos en España durante los últimos cinco años (2011-2015) a través de una metodología de análisis cuantitativo. Se han examinado variables como la tipología y motivación del delito, los lugares donde se cometen y su distribución territorial. A continuación, se investiga el perfil de las víctimas y de los agresores y las variables sexo, edad y nacionalidad.

Las fuentes para la investigación de estas cifras han sido las memorias de la Fiscalía de Delitos de Odio de Barcelona, los informes Raxen elaborados por la organización Movimiento contra la Intolerancia y los datos recogidos por la $O I D D H$ dentro del proyecto europeo "Stop Hate Crimes in Europe".

Desde el Ministerio del Interior del gobierno de España se han utilizado los dos únicos informes específicos de delitos de odio publicados en 2014 y 2015 en los que se recopilaron 
y desglosaron datos de las Fuerzas y Cuerpos de Seguridad. Los datos incluyen cualquier hecho que infrinja el orden penal y administrativo y que se ejecute contra una persona por su pertenencia, a una etnia, raza, religión o práctica religiosa, discapacidad, orientación o identidad sexual, así como por su situación de pobreza y exclusión social.

En 2012 se incluyeron incidentes racistas y xenófobos (pero sin calificarlos ni incluir la categoría de delitos de odio) en el "Anuario estadístico" del Ministerio del Interior. En 2011 estos incidentes se publicaron en el "Informe anual del Consejo para la promoción de la igualdad de trato y no discriminación de las personas por el origen racial o étnico" publicado por el Observatorio Español contra el Racismo y la Xenofobia.

\section{Evolución global de los delitos de odio en España (2011-2015)}

El Ministerio de Interior español registra y publica por primera vez las cifras de los delitos de odio en España en 2013 en el "Informe sobre la evolución 2013 de los delitos de odio en España". Estos datos se publicaban en otros estados a través de la OIDDH desde 2011. Hasta el momento la Fiscalía de Delitos de Odio de Barcelona dirigida por Miguel Ángel Aguilar desde 2010 y otras organizaciones como Movimiento contra la Intolerancia a través del programa internacional "Stop Hate Crimes" de la OIDDH han registrado también los datos de este tipo de delitos.

No obstante, como sucede en otros países, determinar las cifras exactas de delitos de odio es complicado, entre otros motivos y como hemos señalado en el primer apartado, por el consenso en su definición, las dificultades para distinguir entre crimen de odio y otra manifestaciones de intolerancia y sobre todo, por la falta de consenso en la legislación interna en los estados.

Los datos analizados muestran un total de 1.285 de delitos de odio registrados durante el 2015, casi un 10\% más que en el año anterior y un 92,84\% más que desde 2011 (gráfico I). No obstante, según la Agencia de Derechos Fundamentales de la Unión Europea el 90\% de los casos contabilizados en Europa no se denuncian (FRA, 2013: 1). En 2010 el "Panel sobre discriminación por origen racial o étnico: la percepción de las potenciales víctimas" reveló que tan sólo "un 4,3\% de las personas que habían vivido situaciones de discriminación manifestó haber denunciado, frente a un mayoritario 94,3\% que no lo hizo" (Observatorio Español contra el Racismo, 2010: 26).

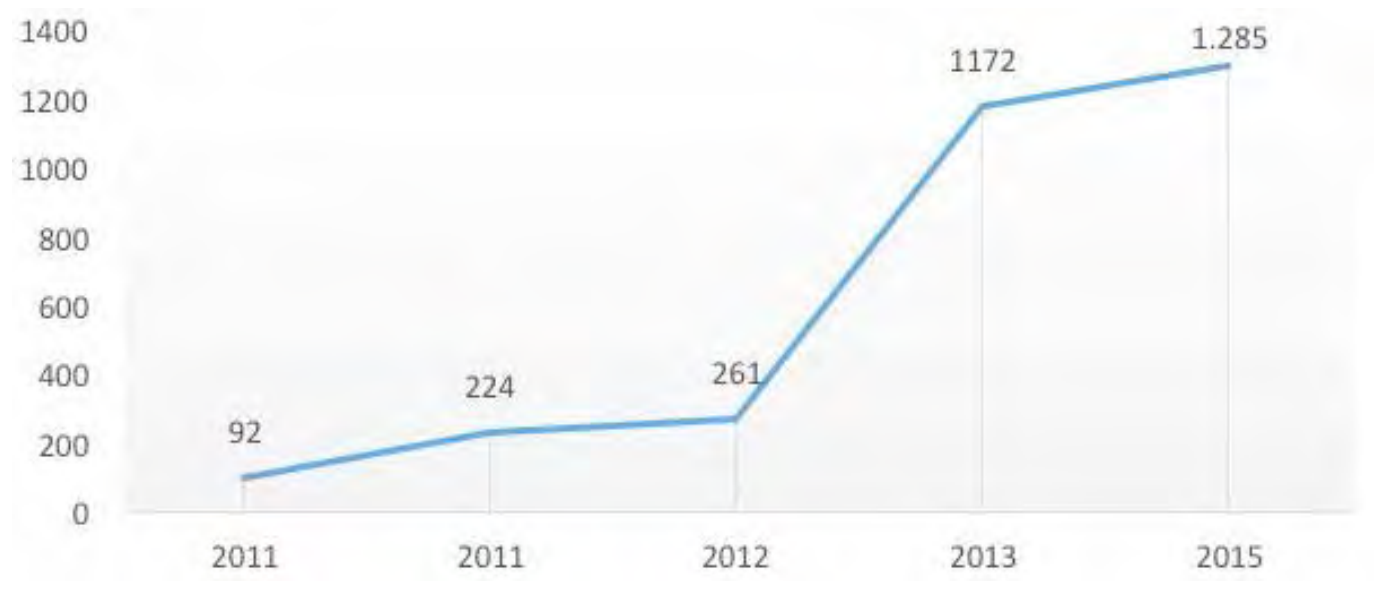

Gráfico I. Evolución global de los delitos de odio en España (2011-2015)

Fuente: Elaboración propia a partir de datos de las Memorias del Servicio del Servicio de Delitos de Odio y Discriminación 2011-2014, los informes anuales sobre delitos de odio en la región OSCE 2011-2015 y los Informes sobre delitos de odio en España 2013-2015. 
Esta cifra no sólo ha aumentado por algunas de las causas señaladas en la primera parte a nivel europeo (aumento de la islamofobia, auge de partidos de extrema derecha, y del "ciber odio"), sino también por el trabajo recolección de datos, de denuncia y visualización de estos delitos por las asociaciones específicas y víctimas directas de los delitos y su difusión en los medios de comunicación.

También se ha producido un incremento en el número de actuaciones por parte del gobierno a través de programas específicos dirigidos a los cuerpos y fuerzas de seguridad del Estado. Destaca el Programa FIRIR (Formación para la Identificación y Registro de Incidentes Racistas), ${ }^{3}$ desarrollado en el marco proyecto europeo "Progress" desde 2012. Su objetivo es el desarrollo de actividades formativas en las Fuerzas y Cuerpos de Seguridad, de los distintos ámbitos territoriales, con el fin de mejorar los procedimientos de identificación y registro de los incidentes racistas y xenófobos (Proyecto Europeo Progress: 2012: 36).

Asimismo hay que destacar que los motivos de las víctimas para no denunciar son diversos: una creencia de que todo es inútil, desconfianza o miedo a la policía, falta de conocimiento de la ley, miedo a desvelar su orientación sexual o la expulsión del país en los casos de racismo y xenofobia hacia inmigrantes (Memoria de la Fiscalía de Delitos de Odio, 2012: 11).

\subsection{Representación territorial de hechos relativos a delitos de odio (2011-2015)}

Las comunidades autónomas de Andalucía, Cataluña, Comunitat Valenciana, País Vasco y Madrid son las que registran un mayor número de delitos de odio en 2015. Estas 5 regiónes representan el $67 \%$ del total de los hechos cometidos en el conjunto estatal (gráfico II).

No obstante, si nos centramos en los últimos dos años, con las cifras obtenidas por el Ministerio del Interior, el número de delitos aumenta en prácticamente todas las comunidades autónomas, excepto retrocesos puntuales en ocho regiónes (Andalucía, Asturias, Canarias, Castilla La Mancha, Extremadura, Galicia, Madrid, La Rioja). Prácticamente en el resto la cifra se incrementa en un 10-15\%. Destaca el caso del País Vasco donde la cifra aumenta de 4 a 117 de delitos (gráfico III).

Una de las principales causas de este crecimiento es la implementación desde 2013 de cursos de formación específica y pedagógica de los delitos de odio, como el Programa FIRIR señalado anteriormente. Además se ha editado el "Manual de apoyo de las Fuerzas y Cuerpos de Seguridad en la identificación y Registro de Incidentes Racistas y Xenófobos" en 2013 y la Guardia Civil y Cuerpo Nacional de Policía, formaron a 400 agentes especializados (Informe de Delitos de Odio, 2013: 5).

Sin embargo, ha sido la voluntad política a nivel municipal y autonómico la que ha permitido desarrollar estos cursos con mayor efectividad. Actualmente sólo la ciudad de Valencia y las comunidades autónomas de Cataluña y Cantabria recogen actuaciones específicas. En el caso valenciano, el 28 de octubre de 2015, la concejalía de Protección Ciudadana del ayuntamiento de Valencia inició una serie de cursos de formación específica para la policía local, dentro del programa sobre delitos de odio organizado por la Organización por la Seguridad y Cooperación en Europa (OSCE).

3 Este programa se elaboró conjuntamente con la Secretaría de Estado de Seguridad y el Observatorio Español contra el Racismo y la Xenofobia (OBERAXE) de la Secretaría General de Emigración e Inmigración del Ministerio de Empleo y Seguridad Social. Destaca la realización de cuatro jornadas de formación, celebradas en la División de Enseñanza y Perfeccionamiento del Cuerpo Nacional de Policía; la edición del "Manual de apoyo de las Fuerzas y Cuerpos de Seguridad en la identificación y Registro de Incidentes Racistas y Xenófobos. Además desde 2013 en los cuerpos de la Guardia Civil y Cuerpo Nacional de Policía se han formado a 400 agentes especializados, se han impartido cursos presenciales a 14.545 agentes y 8.246 se han podido aprovechar de la formación on line. (Memoria del Servicio de Delitos de Odio y Discriminación de la Fiscalía de Barcelona, 2014: 14) 


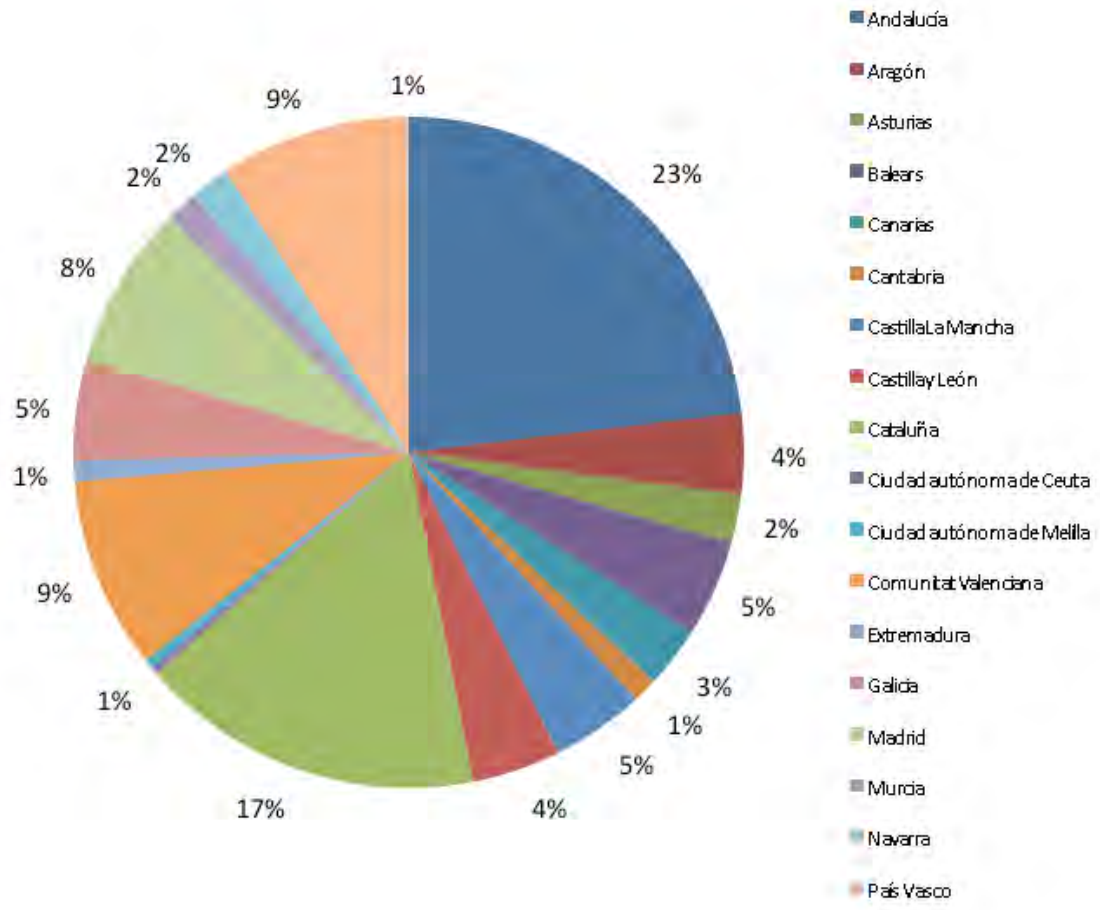

Gráfico II. Distribución de delitos de odio por comunidades autónomas en 2015

Fuente: elaboración propia con datos del Informe sobre delitos de odio en España 2015 del Ministerio del Interior.

En la Memoria 2015 de la Fiscalía de la comunidad de Cantabria (2015: 157) incluye por primera vez la realización del "Protocolo de actuación de las Fuerzas y cuerpos de Seguridad para los delitos de odio y conductas que vulneran las normas legales sobre discriminación”, en el que se exponen, entre otros, los indicadores de los delitos de odio con el objetivo de "erradicar las conductas que atentan contra la igualdad y que ponen en peligro la normal convivencia" y como la Memoria de la Fiscalía indica, este "Protocolo es una excelente noticia, que esperemos sirva para que en la próxima memoria podamos exponer sus frutos".

\section{2 .La motivación del delito}

Las "motivaciones" que conducen a cometer un delito de odio comprenden las "opiniones preconcebidas negativas, ideas estereotipadas, la intolerancia o el odio dirigido a un determinado grupo que comparte una característica común, como raza, el origen étnico, idioma, religión, nacionalidad, orientación sexual, género o cualquier otra fundamental característico" (OSCE, 2003: 13). Las variables ${ }^{4}$ utilizadas para cuantificar la motivación del

\footnotetext{
4 La variable "orientación sexual" se refiere a hechos motivados en diferencias sexuales (gay, lesbiana, heterosexual); "creencias o prácticas religiosas" incluyen hechos motivados por sentimientos contrarios a determinadas religiones (judíos, católicos, protestantes, testigos de Jehová, musulmanes, otros; "discapacidad engloba acto contra la víctima que se realiza prevaliéndose de su discapacidad, cualquiera que fuera (física, psicológica, ancianidad....)."orientación política" se atribuye a hechos motivados por sentimientos contrarios a determinadas ideologías; "racismo y xenofobia" se considera cualquier incidente, que es percibido como racista o xenófobo
} 


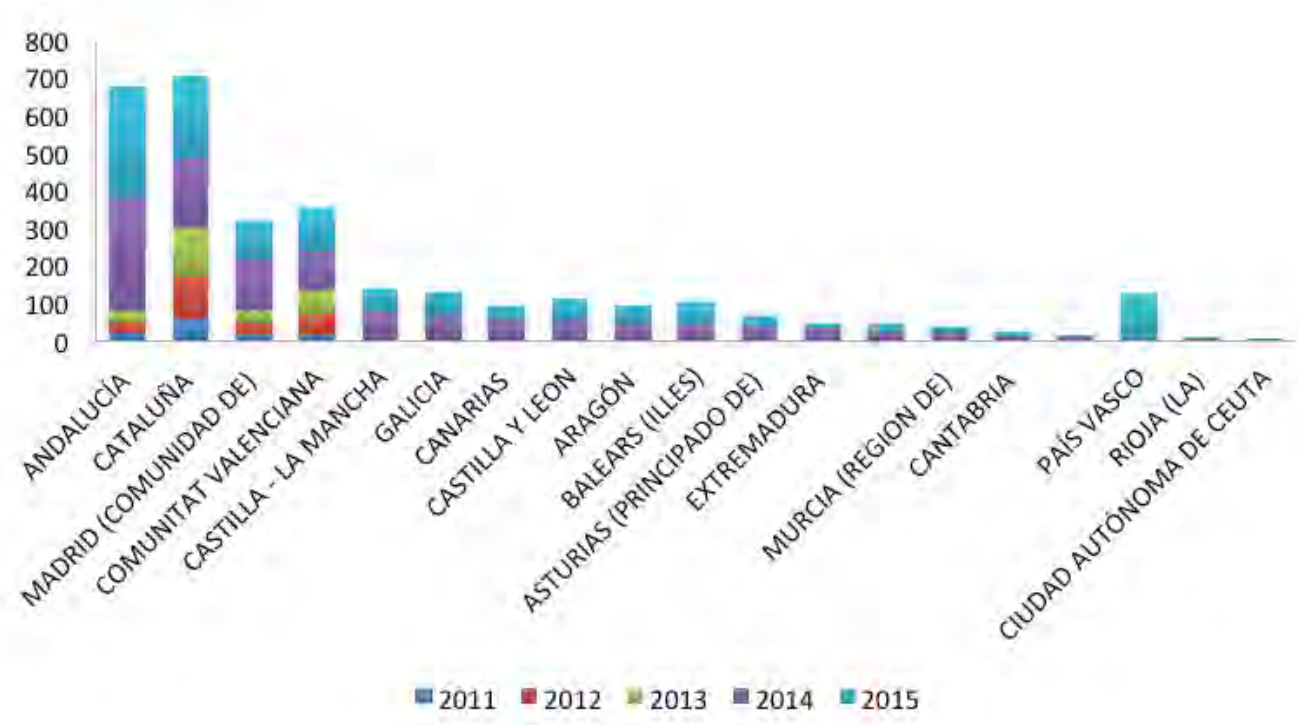

Gráfico III . Evolución de los delitos por comunidades autónomas (2011-2015)

Fuente: Elaboración propia a partir de datos de las Memorias del Servicio del Servicio de Delitos de Odio y Discriminación 2011-2014, los informes anuales sobre delitos de odio en la región OSCE 2011-2014 y los Informes sobre delitos de odio en España 2013, 2014 y 2015.

delito se han establecido de acuerdo a los criterios del Ministerio del Interior y el Programa FIRIR: "orientación sexual", "creencias o práctica religiosa", "discapacidad", "ideología política" y "racismo o xenofobia".

La orientación sexual, el racismo y la xenofobia mantienen los porcentajes más elevados desde 2011 hasta la actualidad. En concreto, estas dos motivaciones representan entre el $55 \%$ y $65 \%$ del total de delitos cometidos desde que se comienza el registro de datos. La discapacidad, la religión y la ideología política tienen índices menores que los dos casos anteriores y repiten la misma tendencia alcista desde 2011 y sus porcentajes son similares (gráfico IV).

Las posibles causas de estas cifras, especialmente en el caso de la xenofobia y racismo, se debe a la transformación demográfica y social que se ha producido en España desde comienzos del siglo XXI , ya que se convierte en un país receptor de inmigrantes y provoca un rechazo de los nacionales con actitudes racistas y xenófobas, fundamentalmente acrecentada durante la crisis económica que comienza a mediados de 2007.

Un estudio de Cea D'Ancona (2004:24) constata que la xenofobia se activa en España (como sucede en otros países europeos) cuando aumenta la presencia de inmigrantes, tanto la "real" como la "transmitida" por los medios de comunicación social. No sólo afecta el número "real", sino también el construido a partir de las noticias que acaparan la atención de los medios. Estas tradicionalmente se han focalizado en la llegada irregular de inmigrantes (pateras, cayucos, saltos de vallas fronterizas,..), contribuyendo a una percepción de la presencia inmigratoria que acaba magnificándose respecto a la "real" o contabilizada por los registros estadísticos. Quillian (1995:592), afirma que "la amenaza percibida está influida tanto por la situación económica como por el tamaño del grupo subordinado".

por la víctima, o cualquier otra persona, incluido el Agente de Policía o cualquier otro testigo; aunque la víctima no esté de acuerdo, así como los actos de odio, violencia, discriminación, fobia y rechazo contra los extranjeros o personas de distintos grupos, debido a su origen racial, étnico, nacional, cultural o religioso. 


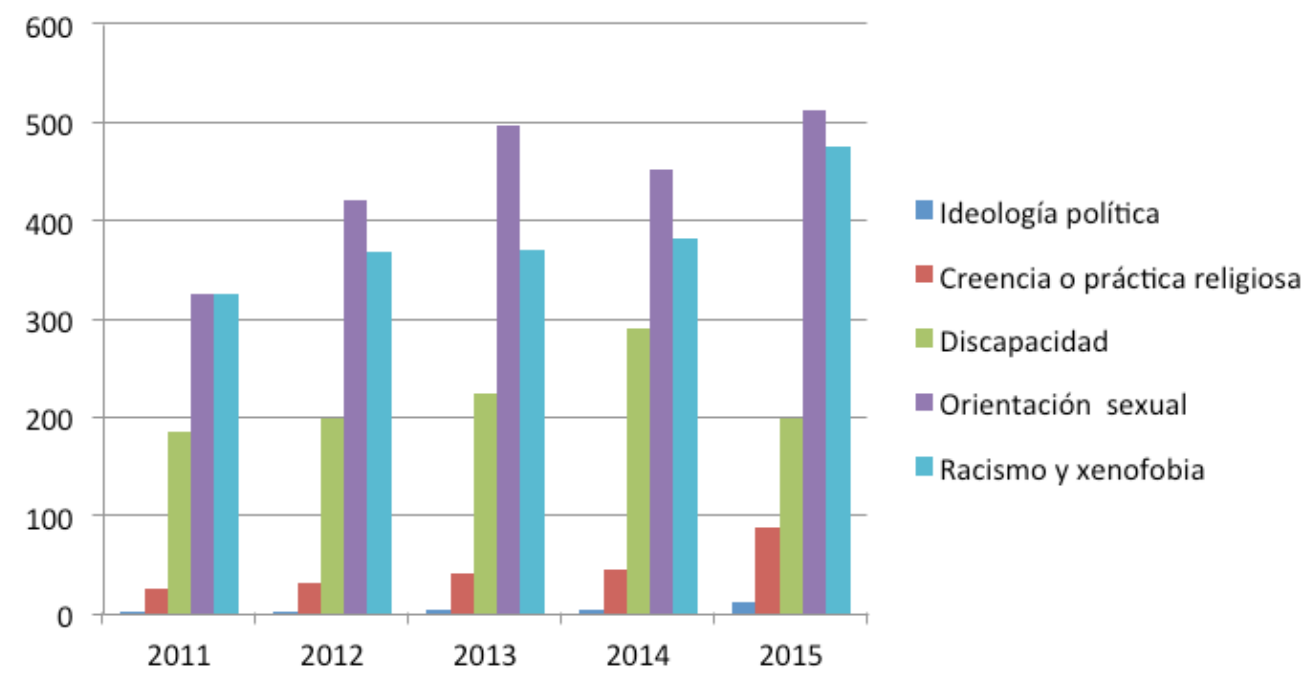

Gráfico IV. Evolución de las motivaciones de los delitos de odio (2011-2015)

Fuente: elaboración propia con datos del Ministerio del Interior (2013-2015), Mossos d'Esquadra (2011-2014) e Informe Raxen (2011-2015)

En este contexto, conviene recordar que en 1997 España era el país que menos porcentaje de población extranjera tenía de la Unión Europea $(1,95 \%)^{5}$. En el año 2011 la cifra se sitúa en un 12,2\%, (gráfico V) porcentaje que casi duplica la cifra conjunta de la Unión Europea $(6,4 \%)^{6}$, según datos publicados desde la oficina europea de estadística, Statistical Office of the European Communities (EUROSTAT) y actualmente la media de población extranjera residente es de $10,1 \%$.

Por comunidades autónomas, la Islas Baleares (17,6\%), Comunitat Valenciana (14\%), Cataluña $(13,7 \%)$ y Madrid $(12,6 \%)$ acogen las cuatro quintas partes de ese crecimiento demográfico. Atendiendo a las variables nacionalidad, religión e idioma proporcionadas por el INE, se registran 122 nacionalidades, 62 idiomas y 15.353 religiones inscritas en el Registro de Entidades Religiosas. Desde 2001 se profesan 12 nuevos cultos en España. El Observatorio del Pluralismo Religioso en España contabiliza 6.125 lugares

de culto de confesiones minoritarias en 2014, una cifra que supone el 21,09\% del total de centros religiosos en España (Observatorio Pluralismo y Democracia, 2014:13).

Esta sociedad multicultural provoca actitudes racistas y xenófobas entre la población nacional. A partir de 2005, tanto los barómetros del CIS como los estudios elaborados por el Observatorio Español de Racismo y Xenofobia, reflejan que la inmigración es una de las mayores preocupaciones para los españoles y la percepción valorativa de la presencia inmigratoria se considera, por la mayoría, como "excesiva" (Oberaxe, 2014: 35). Esta valoración es más probable a mayor edad del encuestado, cuando su nivel educativo baja o cuando desciende la cualificación profesional y los ingresos. También destaca entre los que ideológicamente se ubican más hacia la derecha o se consideran creyentes practicantes. (Oberaxe, 2014: 42).

La crisis económica que comienza en 2007 genera cambios en las actitudes, como el retroceso en el ámbito de los derechos, en concreto en los derechos de sufragio y de nacio-

5 Las cifras de población provienen de la revisión del Padrón de Habitantes a 1 de enero de cada año.

6 El porcentaje de 6,4\% de tasa de inmigración hace referencia a la Unión Europea formada por 27 Estados y cuyo porcentaje se ha obtenido a través de la Oficina Estadística de la UE (Statistical Office of the European Communities (EUROSTAT). 


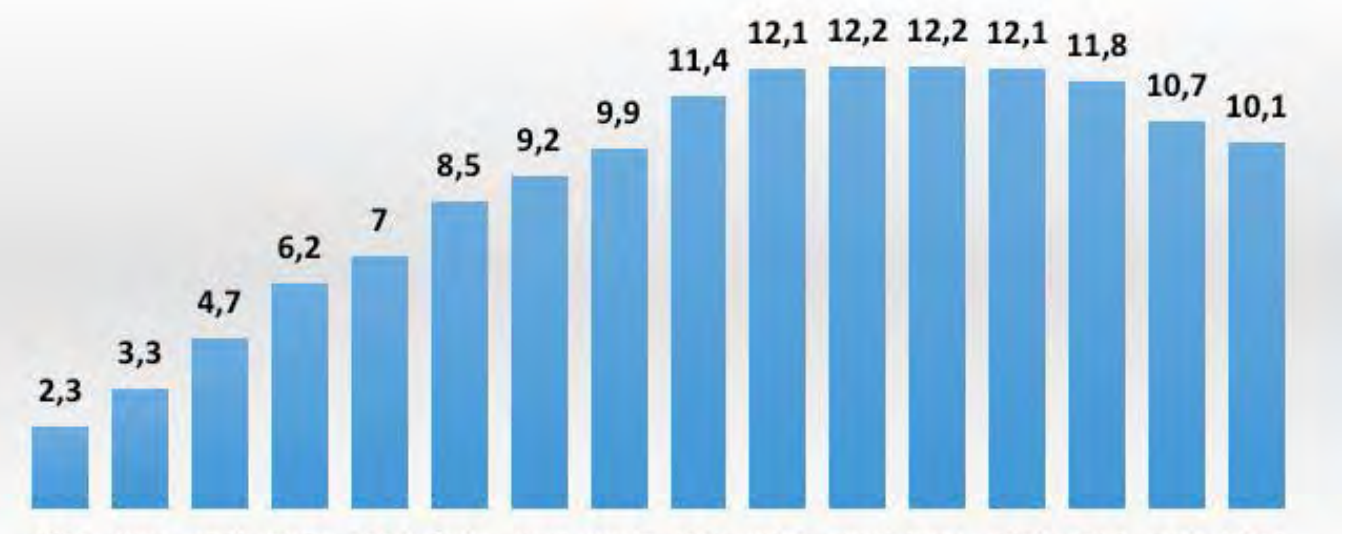

2000200120022003200420052006200720082009201020112012201320142015

Gráfico V. Evolución de los porcentajes de extranjería en España. 2000-2015

Fuente: elaboración propia con datos del INE (2000-2015)

nalidad y provoca "la evolución de las opiniones inicialmente favorables a la equidad legal hacia los discursos de preferencia de los nacionales frente a los foráneos en el acceso a derechos sociales y en el acceso a un puesto de trabajo" (Manual de apoyo a las fuerzas y cuerpos de seguridad en la identificación y registro de incidentes racistas o xenófobos, 2012: 21). Bommes y Geddes (2010: 34) advierten que "el aumento de la xenofobia correlaciona con períodos de alta inmigración. También se conexiona con períodos de crisis económica cuando la aminoración de recursos (empleo, prestaciones sociales, servicios públicos,..) eleva la competencia entre quienes los precisan.

\subsection{El lugar de la comisión del delito}

Las viviendas y la vía pública son los espacios más comunes para la perpetración de los delitos de odio (alrededor del 70\%) desde 2011 y hasta la actualidad (gráfico VI). Destaca la comisión de delitos en centros religiosos, especialmente en mezquitas y centros que profesan el Islam y en los campos de fútbol que están vinculados con los grupos ultras de los equipos de tendencia neonazi. La magnitud de este problema - muy presente en los medios de comunicación - ha provocado su regulación a través de Ley 19/2007, de 11 de julio, la violencia, el racismo, la xenofobia y la intolerancia en el deporte. El objetivo central de esta Ley es erradicar la violencia en el deporte, además de prevenir, controlar y sancionar con rigor cualquier manifestación violenta en el ámbito de la actividad deportiva, especialmente, cuando adquiere connotaciones de signo racista, xenófobo o intolerante.

\subsection{Las tipologías penales}

Los delitos de odio pueden incluir amenazas, daños a la propiedad, asalto, asesinato o cualquier otro delito cometido con una motivación.

En España las ocho tipologías que destacan especialmente son las lesiones, el abuso sexual, las amenazas, las vejaciones leves, las agresiones sexuales, las injurias, y los actos racistas, xenófobos e intolerantes en el deporte, especialmente en los campos de fútbol.

Las lesiones, amenazas y actos racistas representan el 75\% del total de los tipos de delitos cometidos desde 2011 (gráfico VII).

Es significativo y alarmante que casi la mitad (un 43\%) de los abusos sexuales, lesiones y amenazas se cometan en grupo. 


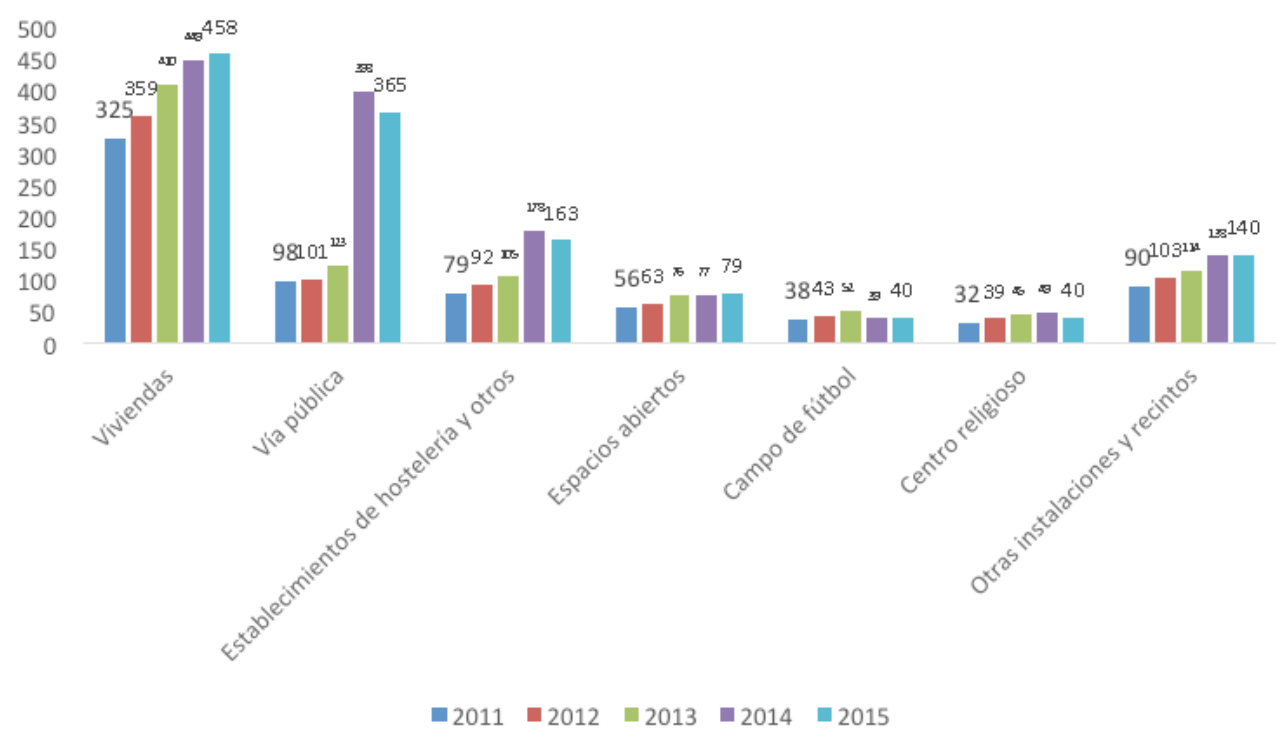

Gráfico VI . Distribución por lugar de la comisión de hecho (2011-2015)

Fuente: Elaboración propia a partir de datos de las Memorias del Servicio del Servicio de Delitos de Odio y Discriminación 2011-2014, los informes anuales sobre delitos de odio en la región OSCE 2011-2014 y los Informes sobre delitos de odio en España 2013, 2014, 2015.

Además esta tendencia aumenta cuando se trata de los hechos racistas y xenófobos perpetrados en el deporte, en concreto, en los campos de fútbol. En este caso, la media de actos cometidos en grupo se dispara hasta el $84 \%$ desde 2011. Uno de los motivos es que los estadios se convierten en uno de los espacios de ocio preferidos por los perpetradores de este tipo de delito que actúan mayoritariamente en grupo y donde sus actos pueden pasar más desapercibidos al mezclarse con la masa.

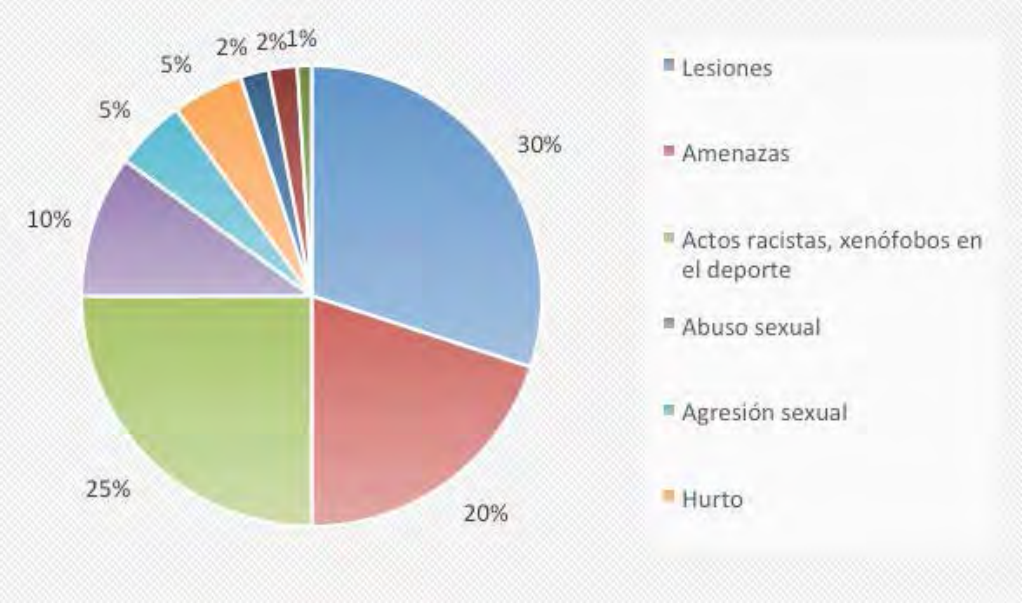

Gráfico VII. Distribución media de las tipologías penales y administrativas de los delitos de odio en España (2011-2015)

Fuente: Elaboración propia a partir de datos de las Memorias del Servicio del Servicio de Delitos de Odio y Discriminación 2011-2014, los informes anuales sobre delitos de odio en la región OSCE 2011-2014 y los Informes sobre delitos de odio en España 2013, 2014 y 2015. 
También los abusos sexuales están muy relacionados con los hechos cometidos contra la orientación o identidad sexual, estando el resto muy repartidos respecto al ámbito concreto de comisión.

\subsection{Perfil de la víctima}

El total de víctimas registradas en el año 2015 por delitos de odio asciende a 1.273, un $20 \%$ más que en 2011. Unas cifras que desde que se empezaron a registrar no han parado de aumentar (gráfico VIII).

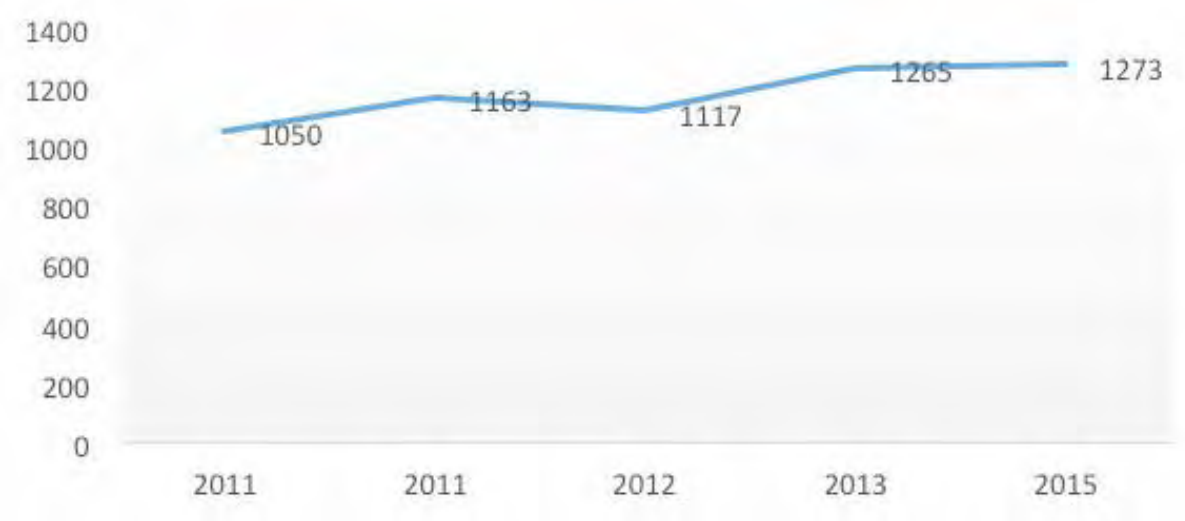

Gráfico VIII. Evolución del número de víctimas de delitos de odio en España (2011-2015) Fuente: Elaboración propia a partir de datos de las Memorias del Servicio del Servicio de Delitos de Odio y Discriminación 2011-5 los informes anuales sobre delitos de odio en la región OSCE 2011-2014 y los Informes sobre delitos de odio en España 2013. 2014 y 2015.

El perfil de la víctima de los delitos de odio repite el mismo patrón en todos los años analizados. Se trata mayoritariamente de mujeres (gráfico IX) entre 18 y 35 años y de nacionalidad española. No obstante, a partir de 2012, la mayoría de las víctimas , tanto varones como mujeres son de origen extranjero. Las agresiones sexuales, el exhibicionismo y las vejaciones leves constituyen los principales tipos de abusos a las que son sometidas. Entre los principales hechos conocidos cometidos contra las víctimas de sexo masculino se encuentran las lesiones y las amenazas.

Hombre Mujer

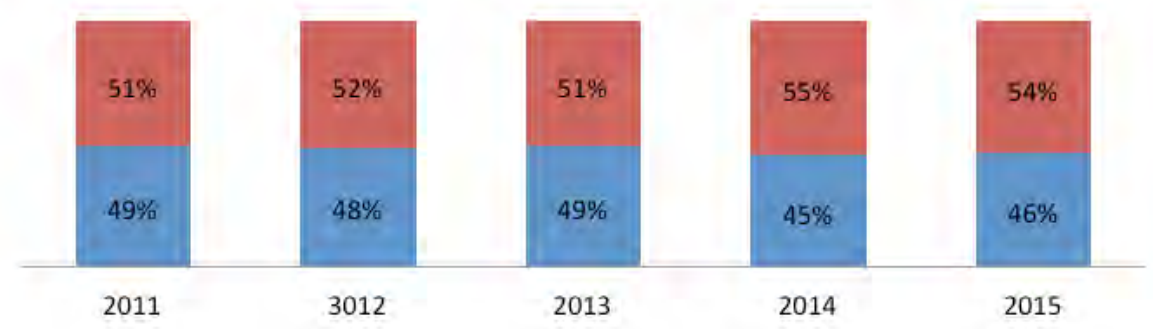

Gráfico IX. Evolución del género de la víctima de delitos de odio (2011-2015)

Fuente: Elaboración propia a partir de datos de las Memorias del Servicio del Servicio de Delitos de Odio y Discriminación 2011-2014, los informes anuales sobre delitos de odio en la región OSCE 2011-2014 y los Informes sobre delitos de odio en España 20132014 y 2015. 
Además se observa que en la distribución global de incidentes según motivación y género, sólo exceden en porcentaje a las víctimas de sexo masculino en dos categorías: la orientación o identidad sexual y la discapacidad.

Respecto a la edad, destaca que una cuarta parte del conjunto de las víctimas desde 2011 pertenezcan al grupo de menores. Sin embargo, la mayoría de las víctimas registradas (alrededor del 40\%) recae entre la franja de edad situada entre los 18 y 35 años (gráfico X).

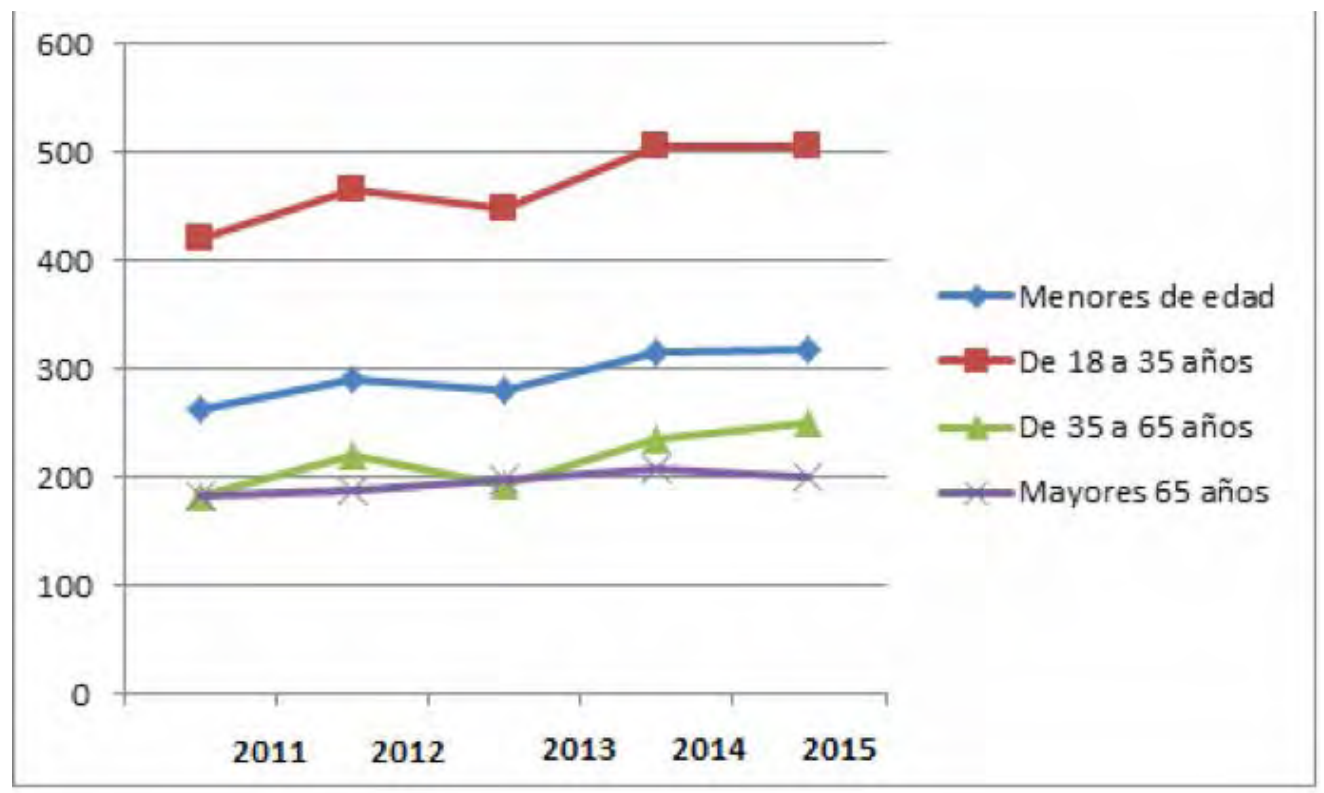

Gráfico X: Evolución por grupos de edad de las víctimas de delitos de odio (2011-2015)

Fuente: Elaboración propia a partir de datos de las Memorias del Servicio del Servicio de Delitos de Odio y Discriminación 2011-2014, los informes anuales sobre delitos de odio en la región OSCE 2011-2014 y los Informes sobre delitos de odio en España 2013, 2014 y 2015.

Por nacionalidades, las víctimas de origen español es el grupo mayoritario, con una media del 60\% entre los años 2011-2012. Sin embargo, la tendencia comienza a invertirse desde 2013 y las cifras de víctimas extranjeras aumentan más del 10\%. A partir de este año, la cifra ha crecido sensiblemente cada año hasta situarse en 2015 en el $58 \%$ de víctimas extranjeras (gráfico XI). Dentro del conjunto de las víctimas de nacionalidad extranjera, son las procedentes de Marruecos, Colombia, Rumanía, Senegal, Bolivia y China las que concentran los valores más elevados.

\subsection{Perfil del perpetrador}

El primer factor destacable de la caracterización del perfil del autor implicado es que se trata prácticamente en su totalidad de varones - la media desde 2011 es del 92,97\% (gráfico XII). Esta tendencia se repite, según la distribución global de incidentes por ámbito y sexos, en todos los ámbitos delictivos registrados por el Sistema Estadístico de Criminalidad (SEC). Se registra el 100\% de varones en los ámbitos de "orientación o identidad sexual", de "creencias o prácticas religiosas" y de "racismo y xenofobia". Esta evidencia es compartida por los terroristas yihadistas, donde los varones están "sobrerepresentados entre quienes se implican en actividades de terrorismo, cualesquiera que sean los actores que los practican, la ideología en que se inspiran o los objetivos que persiguen" (Reinares y García, 2013: 14). 


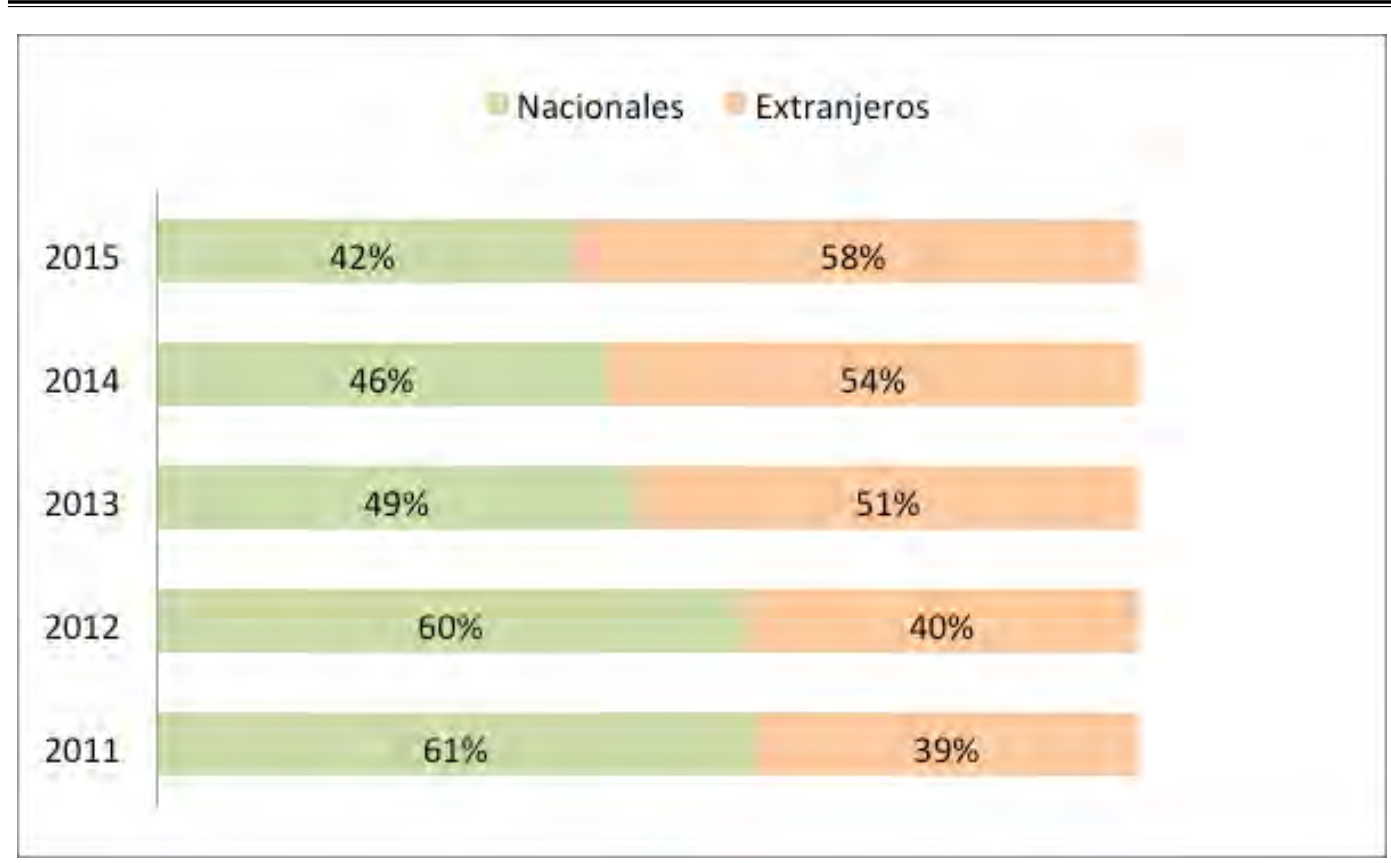

Gráfico XI. Evolución del origen de las víctimas de delitos de odio en España (2011-2015)

Fuente: Elaboración propia a partir de datos de las Memorias del Servicio del Servicio de Delitos de Odio y Discriminación 2011-2014, los informes anuales sobre delitos de odio en la región OSCE 2011-2014 y los Informes sobre delitos de odio en España 2013, 2014 y 2015.

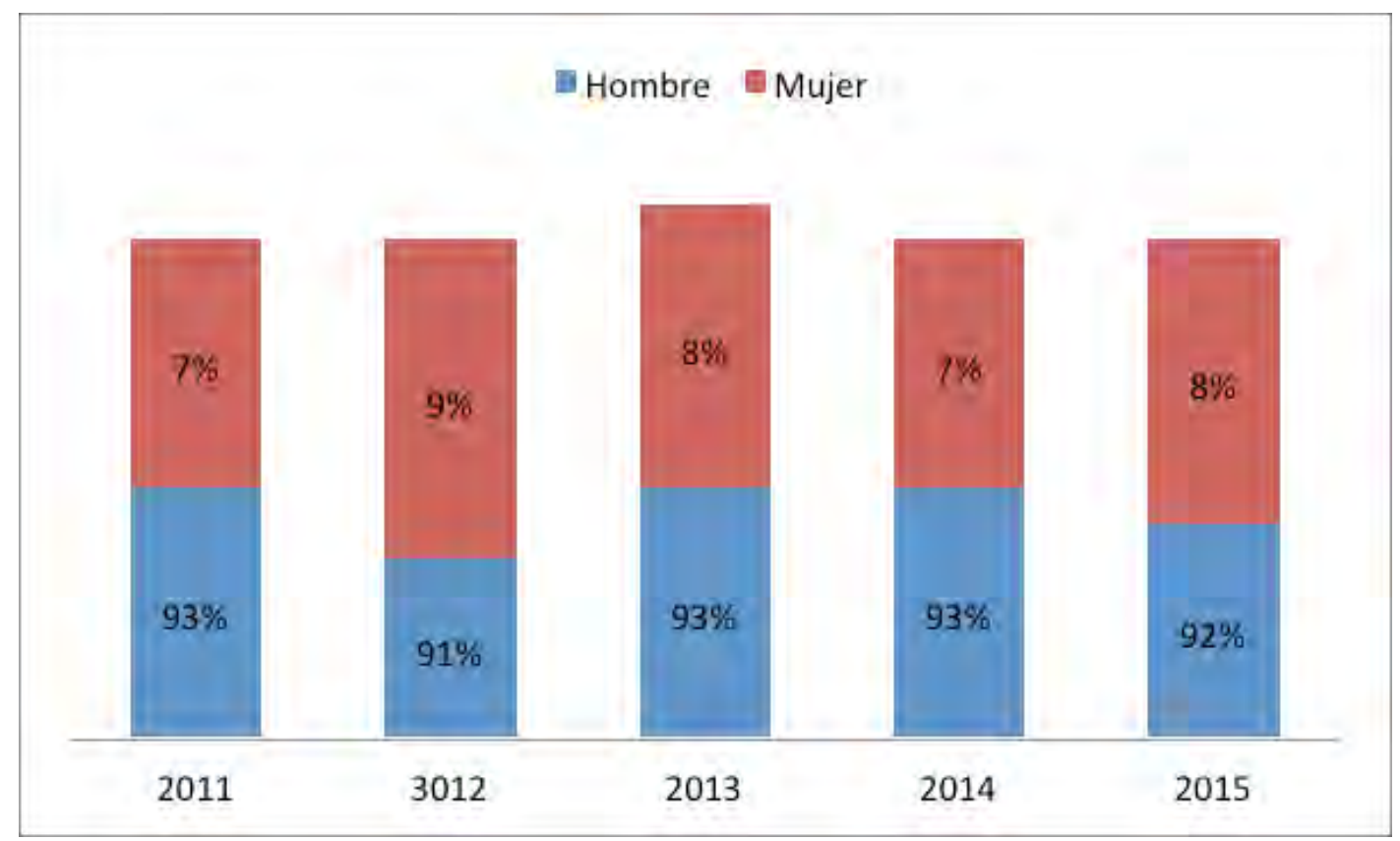

Gráfico XII. Distribución de los autores de delitos de odio según género.

Fuente: Elaboración propia a partir de datos de las Memorias del Servicio del Servicio de Delitos de Odio y Discriminación 2011-2014, los informes anuales sobre delitos de odio en la región OSCE 2011-2014 y los Informes sobre delitos de odio en España 2013, 2014 y 2015. 
Además de varones, los autores desde 2011 tienden a estar en la franja de edad de 18 a 35 años y esta cohorte de edad es la que más aumenta anualmente (gráfico XIII). En concreto, desde 2010 ha aumentado un 74\%.. La mediana se ubica en los 29,4 años, la moda en los 28 y la media en los 31,2 . Datos que además reflejan que el inicio de la implicación en este tipo de delitos se sitúa en torno a los 30 años.

Este rasgo no es exclusivo de los autores de los delitos de odio, ya que como señala Ackerman (2007: 55) "la juventud es una particularidad aplicable en fenómenos de terrorismo y en la práctica de la violencia y de sus manifestaciones modernas". Asimismo, la propaganda del discurso del odio - como la de otras organizaciones terroristas modernas como el yihadismo - apela principalmente a la movilización de los jóvenes, considerados el grupo más vulnerable. Al mismo tiempo, los jóvenes son los mayoritariamente usuarios de nuevas tecnologías y las redes sociales, el medio de propaganda y difusión preferido para esta ideología —el odio—debido a su carácter de inmediatez, anonimato e impunidad.

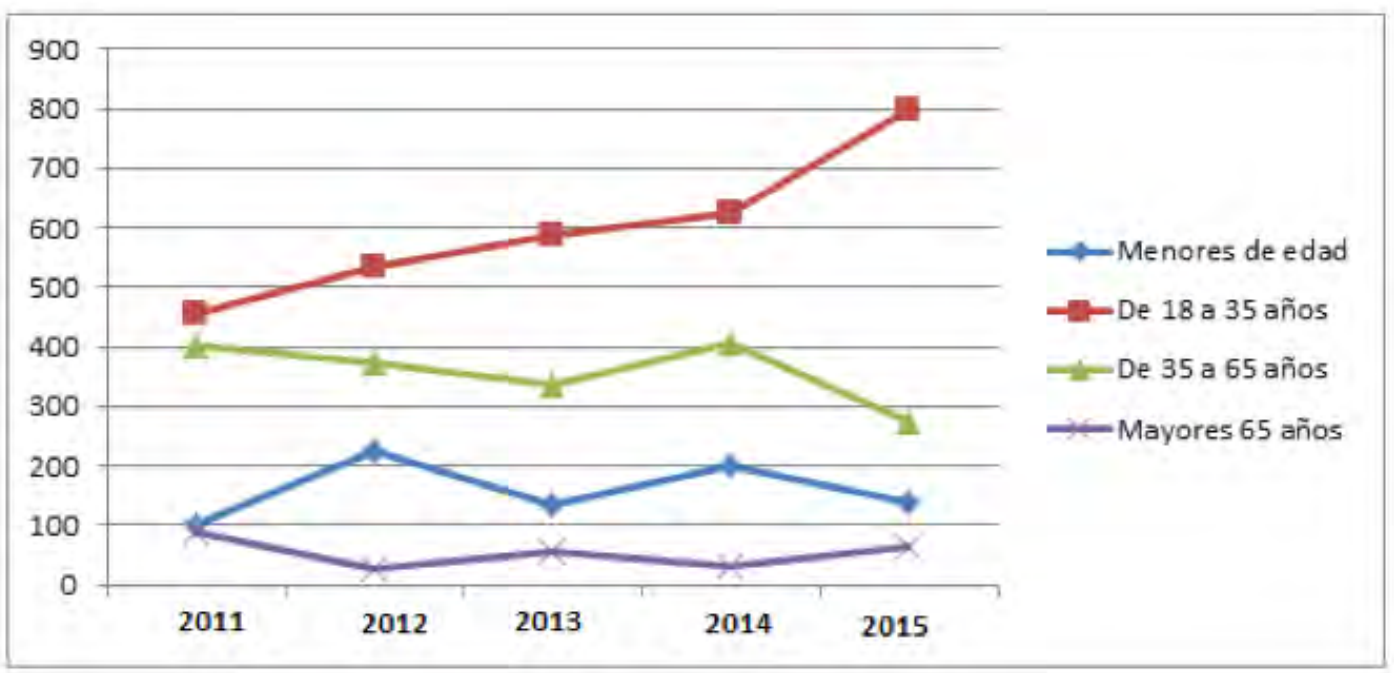

Grafico XIII: Evolución por grupos de edad de las autores de delitos de odio (2011-2015)

Fuente: Elaboración propia a partir de datos de las Memorias del Servicio del Servicio de Delitos de Odio y Discriminación 2011-2014, los informes anuales sobre delitos de odio en la región OSCE 2011-2014 y los Informes sobre delitos de odio en España 2013, 2014 y 2015.

\section{Conclusiones}

El análisis de las cifras de los delitos de odio en España han proyectado un escenario preocupante. Se han registrado 1.285 delitos de odio durante 2015, casi un $10 \%$ más que en el año anterior y un 92,84\% más que desde 2011. Las lesiones, amenazas y actos racistas representan el 75\% del total de los tipos de delitos cometidos desde 2011.

Los agresores son mayoritariamente varones, entre 18 y 35 años y ocho de cada diez son nacionales. Es significativo y alarmante que casi la mitad de los abusos sexuales, lesiones y amenazas (43\%) se cometan en grupo.

El total de víctimas registradas en el año 2015 asciende a 1.273, un 20\% más que en 2011. Unas cifras que desde que se empezaron a registrar no han parado de aumentar. El $52 \%$ de las víctimas son mujeres y han nacido en España, aunque cada vez más el origen de todas las víctimas es más diverso tanto en su país de origen como en su religión. Destaca en este informe y en los analizados desde el Ministerio del Interior que una cuarta parte del conjunto de las víctimas son menores de edad. 
Otro crecimiento preocupante es la comisión de delitos en centros religiosos, especialmente en mezquitas y centros que profesan el Islam y en los campos de fútbol que están vinculados con los grupos ultras de los equipos de tendencia neonazi.

Andalucía, Cataluña, Comunitat Valenciana, Madrid y País Vasco son las comunidades donde se contabilizan mayor tipo de delitos, entre otras causas porque existen fiscalías específicas y se han impartido cursos de formación a las fuerzas y cuerpos de seguridad del estado. Dos factores que permiten el registro de este tipo de delitos, ya que como se ha señalado en el artículo, el desconocimiento es una de las principales causas del bajo nivel de registros.

También en este estudio se han apuntado otras causas vinculadas a la naturaleza del delito, como es el porcentaje de inmigración: existe una relación entre las comunidades con mayor población inmigrante y más delitos de odio cometidos.

Además el crecimiento de delitos de odio en España, como sucede en el resto de la Unión Europea está muy relacionado con el discurso del odio propagado especialmente a través de las nuevas tecnologías, el denominado "ciber odio".

Otro de los factores que explican el crecimiento de las cifras de delitos de odio es el éxito en las urnas de partidos de extrema derecha a nivel internacional y el contagio de su discurso en formaciones y movimientos. Ejemplos como el Front National Francés o España 2000 expuestos en la segunda parte del artículo evidencian que son fuente de delitos de odio y los tribunales han comenzado a condenarlos.

No obstante, si un sistema de justicia penal no utiliza el concepto de delito de odio, el motivo no se reconoce como un elemento esencial de la infracción y por lo tanto, la existencia de crímenes de odio seguirá siendo invisible.

De hecho, se producen los crímenes de odio en mayor o menor medida en todos los países de la UE, aunque los que han desarrollado mecanismos eficaces de recopilación de datos suelen mostrar los niveles más altos de odio delitos. Como señala la última memoria de la Fiscalía de delitos de odio de Barcelona (2014: 35), "a pesar de que no existan leyes específicas para hacer frente a los crímenes de odio en nuestro país, si la policía, los fiscales y los jueces pueden ser entrenados para comprender y responder a estos delitos con eficacia, los daños causados por los delitos de odio pueden disminuir".

La legislación es sólo una parte de la respuesta al problema de crimen de odio, en combinación con otras herramientas que puede ser un poderoso catalizador para cambios en las actitudes sociales.

\section{Bibliografía}

Ackerman, B (2007), Antes de que nos ataquen de nuevo. La defensa de las libertades en tiempos de terrorismo. Barcelona, Península

Agencia de Derechos Fundamentales de la Unión Europea (2011), Combating hate crime in the EU: Giving victims a face and a voice. Lituania, FRA

- (2013), Annual Report 2013. Lituania, FRA

Aguilar, M. Á. (2011). "La reforma del art. 510 del Código Penal. La Ley Penal", Revista de Derecho Penal, Procesal y Penitenciario, 86: 5-13.

American Psychologist Association. (2014). "The Psychology of Hate Crimes", APA, 16: 70-95.

Boeckmann, R. J., y Turpin-Petrosino, C. (2002). "Understanding the Harm of Hate Crime". Journal of Social Issues, 58: 207-225.

Bommes, M. y Geddes, A. (2000). Immigration and Welfare. Challenging the borders of the welfare state. Londres, Routledge.

Canas, G. (2015). "Marine Le Pen, juzgada por incitar al odio racial contra los musulmanes". El País, 20 de octubre. Disponible en línea en http://internacional.elpais. com/internacional/2015/10/20/actualidad/1445329835_872529.html [Consultado: $1 / 11 / 2105]$ 
Cea d'Ancona, A. (2004). La activación de la xenofobia en España. ¿Qué miden las encuestas?. Madrid, CIS

Comisión Europea contra el Racismo y la Intolerancia (2011) . Cuarto Informe sobre España sobre la situación del racismo y la xenofobia. Estrasburgo, ECRI

De Cózar, Á. y Gómez, J. (2011) . "79 minutos con Anders Behring Breivik matando". El País, 31 de julio. Disponible en línea en http://www.elpais.com/articulo/reportajes/79/minutos/Anders/Behring/Breivik/matando/elpepusocdmg/2011073 1elpdmgrep_1/Tes [Consultado: 15/10/2105]

Fiscalía de Delitos de Odio de Barcelona (2010). Memoria anual de los delitos de odio. Barcelona: Fiscalía de Delitos de Odio de Barcelona.

-(2011). Memoria anual de los delitos de odio. Barcelona: Fiscalía de Delitos de Odio de Barcelona.

-(2012). Memoria anual de los delitos de odio. Barcelona: Fiscalía de Delitos de Odio de Barcelona.

-(2013). Memoria anual de los delitos de odio. Barcelona: Fiscalía de Delitos de Odio de Barcelona.

-(2014). Memoria anual de los delitos de odio. Barcelona: Fiscalía de Delitos de Odio de Barcelona

Fiscalía de la comunidad autónoma de Cantabria (2015). Memoria 2015 (ejercicio 2014). Santander: Fiscalía de la comunidad autónoma de Cantabria .

Gerstenfeld, P. B. (2004). Hate Crimes: Causes, Controls, and Controversies .London, SAGE.

Hall, N. (2013). Hate Crime. New York, Routledge.

Jordán, J. (2001).”Anders Behring Breivik: algunas consideraciones sobre la figura del 'lobo solitario' terrorista", Grupo de Estudios sobre Política y Seguridad Internacional, 7: 1-4.

Ministerio del Interior de España (2011). Estrategia de Seguridad y Defensa Española. Madrid: Ministerio del Interior.

-(2013).Informe sobre delitos de odio en España 2013. Madrid: Ministerio del Interior.

-(2014).Informe sobre incidentes relacionados con los delitos de odio en España. Madrid: Ministerio del Interior.

-(2015).Informe sobre incidentes relacionados con los delitos de odio en España. Madrid: Ministerio del Interior.

Movimiento contra la Intolerancia (2012). Informe Especial Raxen. Europa en Crisis: Tolerancia o Barbarie: Racismo, Xenofobia e Intolerancia en Internet. Madrid, Movimiento contra la Intolerancia.

-(2014). Informe Raxen. Madrid, Movimiento contra la Intolerancia.

Ley orgánica 10/1995, de 23 de noviembre, del Código penal. Boletín Oficial del Estado, 24 de noviembre de 1995.

Observatorio Español contra el Racismo y la Xenofobia (2010). Panel sobre discriminación por origen racial o étnico: la percepción de la posibles víctimas. Madrid, Ministerio de Empleo y Seguridad Social.

(2014). Inmigración, racismo y xenofobia en la España del nuevo contexto europeo. Madrid, Ministerio de Trabajo y Asuntos Sociales

Observatorio Pluralismo y Democracia (2014). Informe sobre la diversidad cultural y religiosa en España. Madrid, Observatorio Pluralismo y Democracia.

Oficina Internacional de Derechos Humanos de la Unión Europea. (2012). Leyes de Delitos de Odio. Una guía práctica de los delitos de odio. Varsovia, OIDDH

Organización para la Seguridad y Cooperación europeoa (2003). Hate Crimes in the OSCE Región: Incidents and Responses. Polonia, OIDDH

Parrilla, J (2015) "Un patriota europeo convoca una concentración ante la mezquita con el lema 'Valentía contra el Islam". Levante EMV, 13 de enero. Disponible en línea en http://www.levante-emv.com/comunitat-valenciana/2015/01/13/patriota-europeo-convoca-concentracion-mezquita/1211373.html [Consultado: 16/11/2105] 
Perry, B. (2001). In the Name of Hate: Understanding Hate Crimes. New York, Routledge.

Poza, P. (2012) "Breivik, condenado a 21 años de prisión por la muerte de 77 personas", El Mundo, 24 de agosto. Disponible en línea en http://www.elmundo.es/elmundo/2012/08/24/internacional/1345764460.html [Consultado: 15/10/2105]

Quillian, L. (1995). "Prejudice as a response to perceived group threat: population composition and anti-immigrant and racial prejudice in Europe”, American Sociological Review, 60:586-611.

Reinares F. y García C. (2013). "Los yihadistas en España: perfil sociodemográfico de condenados por actividades terroristas o muertos en acto de terrorismo suicida entre 1996 y 2012”. Documentos de trabajo Real Instituto el Cano. Disponible en línea en http://www.realinstitutoelcano.org/wps/portal/rielcano/contenido?WCM_ GLOBAL_CONTEXT=/elcano/elcano_es/zonas_es/dt11-2013-reinares-garciacalvo-yihadistas-espana-perfil-sociodemografico-1996-201 2 [Consultado: $16 / 11 / 2105]$

Unión Europea (2012). "Recomendación de la Comisión, de 20 de septiembre de 2012, sobre xenofobia y racismo". Diario Oficial de la Unión Europea L 243, 20 de septiembre de 2012, pp. 23-31.

Unión Europea (2004). "Decisión no 607/2004/UE del Consejo Permanente de la OSCE, de 1 de abril de 2004, sobre los delitos de odio". Diario Oficial de la Unión Europea L 246, 1 de abril de 2004, pp. 5-10.

Vicente, A. (2015). "Los musulmanes franceses temen un rebrote islamófobo" El Pais, 17 de noviembre. Disponible en línea en http://internacional.elpais.com/internacional/2015/11/16/actualidad/1447706202_688256.html [Consultado: 2/12/2105]

Yarnoz, C. (2015). "Francia destina 100 millones contra el auge .de la islamofobia”. El Pais, 17 de abril. Disponible en línea en http://internacional.elpais.com/internacional/2015/04/17/actualidad/1429273020_083674.html [Consultado: 18/10/2105] 